\title{
Protección Social y Transformaciones de las Políticas Sociales en Argentina
}

\author{
Alejandro Del VALLE* \\ JEREMÍAS BOGA DANTE**
}

Social Protection and Social Policy Changes in Argentina

8003

RESUMEN - El presente trabajo se propone analizar el sistema de protección social y las políticas sociales en Argentina. Para ello, se desarrollan las características de la protección social en el país y los diferentes programas de lucha contra la pobreza que se han implementado desde las reformas efectuadas en la década de los '90. Posteriormente, se consideran las transformaciones que el sistema ha tenido desde el año 2003, especialmente en materia previsional, de asignaciones familiares y de cobertura para los jóvenes. Luego se desarrollan los principales programas de transferencias monetarias, destacando las líneas vigentes de los mismos, especialmente el Programa Argentina Trabaja (Ingreso social con trabajo, entre otros.) Se concluye que la actual disposición de prestaciones sociales mantiene y profundiza la estructura de riesgos sociales existente, ya que las transferencias del Estado pueden ser interpretadas como una subvención estatal a las empresas del sector informal.

Palavras-chave - Estado. Protección social. Políticas sociales. Riesgos sociales.

ABSTRACT - This paper analyzes the system of social protection and social policies in Argentina. To do this, the characteristics of social protection system and the different programs to combat poverty which have been implemented since the reforms made in the 90,are developed.. Later, we consider the changes that the system has had since 2003, especially in security matters, family allowances and coverage for young people. The main cash transfer programs are then developed, highlighting the current line thereof, especially the Argentina Works Program (Entry with social work, among others.) We conclude that the current provision of social benefits maintains and deepens the structure of social risks existing as state transfers can be interpreted as a state grant to companies in the informal sector.

Keywords - State. Social protection. Social. Policy. Social risks.

* Doctor en Sociología. Docente e investigador de la Facultad de Ciencias de la Salud y Servicio Social de la Universidad Nacional de Mar del Plata (UNMdP), Mar del Plata - Argentina.E-mail: ajax@speedy.com.ar

** Licenciado en Servicio Social. Docente de la Facultad de Ciencias de la Salud y Servicio Social de la Universidad Nacional de Mar del Plata (UNMdP), Mar del Plata - Argentina.E-mail: danteboga@hotmail.com

Submetido em: setembro/2015. Aprovado em: outubro/2015. 
E acceso a los servicios y al consumo se desarrolla por medio de recursos que provienen del mercado de trabajo, que es el principal medio para obtener ingresos en los hogares, conjuntamente con prestaciones asociadas con los sistemas de protección social, las políticas sociales y la infraestructura social.

En este sentido, los sistemas de protección social expresan un doble compromiso: conciliar la independencia individual con la responsabilidad colectiva. En efecto, los modernos sistemas de protección social fueron construidos sobre la base del compromiso con un nuevo derecho trascendiendo la idea de que es responsabilidad de los individuos superar todas las dificultades y riesgos asociados a la economía de mercado por lo que se puede afirmar que los sistemas de protección social institucionalizan una responsabilidad colectiva.

Sin embargo, en el caso de los países latino americanos, no existe ni ha existido, un desarrollo de instituciones de bienestar como el que se constituyó en Europa Occidental. Al mismo tiempo, la mundialización ha hecho emerger nuevos parámetros de competitividad por lo que se imponen nuevos objetivos de largo plazo en materia de educación, innovación y ciencia y tecnología, a la vez que ofrece oportunidades y desafíos a través de su efecto sobre los niveles de empleo y de salarios. El desafío, entonces, se plantea como: tener la capacidad para competir en un mercado mundial globalizado y, al mismo tiempo reducir los niveles de pobreza y exclusión afianzando un sistema de protección social en un contexto donde la globalización tiende a generar incertidumbre entre nuestros países.

En Argentina la situación es compleja no solo por la heterogeneidad estructural de la economía sino también por la informalidad laboral, la inestabilidad del crecimiento, el heterogéneo nivel de protección social entre provincias y la fuerte inequidad producto de una profunda desigualdad en la distribución del ingreso.

En este contexto, la discusión sobre la protección social no puede mantenerse en el terreno normativo debido a que el riesgo de una 'fragmentación social' tiene una dimensión política concreta: una sociedad donde un tercio de la población no alcanza a acceder a un mínimo de protección social, donde queda aislada de los procesos socio-políticos y termina entre la escasez de recursos y la incapacidad para acceder por canales normalizados a la obtención de los mismos, se transforma en un mundo donde el escenario urbano deja de ser un espacio de integración y donde los procesos sociales profundizan el debilitamiento de la cohesión dificultando cualquier proceso ulterior para el desarrollo.

La capacidad de crear gobernabilidad ante brechas salariales y sociales; la construcción de instituciones confiables que gocen de legitimidad ciudadana; el desarrollo de redes de protección social que resguarden a las personas de los riesgos sociales y de la inestabilidad del crecimiento económico; etc; nos obligan a pensar en nuevas políticas públicas con capacidad para enfrentar las crisis laborales y garantizar el acceso a los beneficios sociales del desarrollo.

En la actualidad, el escenario político se transforma en el lugar donde prima la táctica por sobre la estrategia por lo que prevalece la visión a corto plazo en el tratamiento de los problemas. En ese escenario el Estado pierde la capacidad de construir propuestas que gocen de un consenso mayoritario y, esto se traduce en la incapacidad del sistema político para emprender políticas públicas eficaces en tres ámbitos clave:

- En primer lugar, políticas orientadas a crear oportunidades de crecimiento económico y empleo, resulta obvio que sin un crecimiento sostenido de la economía, no se obtienen los recursos mínimos para el financiamiento responsable de políticas sociales. Pero además existe una profunda dificultad para que el dinamismo de la economía genere una oferta de empleos de buena calidad.

- Segundo, políticas públicas orientadas a aumentar las capacidades de las personas, vale decir, a la educación y la capacitación laboral. Por cierto, el requisito mínimo es cumplir con las metas de desarrollo del Milenio. Pero no basta con cumplirlas en términos de 
cobertura sino que es necesario ofrecer educación de buena calidad a toda la población, saber educar en el respeto a la diferencia y dar un salto cualitativo y cuantitativo en materia de inversión en innovación, ciencia y tecnología.

- En tercer lugar, políticas públicas orientadas a la solidaridad, esto es, a una protección social basada en los derechos. Los sistemas que dependen solamente de los aportes contributivos tienen una cobertura cada vez menores $y$, además, reproducen las desigualdades provenientes de la mala distribución del ingreso.

En el presente artículo el objetivo es brindar una breve descripción del sistema de protección social argentino y analizar las características principales que presenta. Para ello, el texto se encuentra estructurado en tres grandes apartados. En el primero se analiza el concepto de protección social y se delimitan sus dimensiones; en el segundo, se analiza el sistema de protección social argentino desde sus principales transformaciones hasta el desarrollo de las diversas áreas que componen a la protección social. Por último, en las conclusiones, se defiende la tesis respecto a que las propias características del sistema de protección social, en Argentina, contribuyen a la consolidación de nuevos procesos de estratificación en el acceso a los derechos sociales y a la condición ciudadana.

\section{Características de la protección social en Argentina}

Hasta la década de 1990 Argentina fue definida como un país pionero dentro del continente en tanto que, junto a Uruguay, se había caracterizado por alcanzar altos grados de cobertura y universalización (aunque de manera estratificada) del bienestar en la población (MESA LAGO, 1989) (FILGUEIRA, 2002).

En términos generales, la protección social en Argentina, es de base contributiva y presenta un amplio desarrollo de la seguridad social que prevalece sobre todos los demás componentes del gasto social (DEL VALLE, 2008: 172). En este sentido, la política social tuvo como ejes fundamentales al empleo y los ingresos por lo que se apoyaba "en transferencias y subsidios al consumo privado, e incentivos a la productividad del trabajador" (DEL VALLE, 2006: 180). Funcionando como un 'sistema de protección compensatorio' las instituciones públicas tenían un papel accesorio respecto del mercado que era el principal proveedor de la satisfacción de las necesidades sociales.

Esto se debió a que durante el período sustitutivo de importaciones (1940-1980) la relación política social - política económica se asentó sobre el rol que había adquirido el estado y se sustentaba en la apropiación de una parte considerable de los recursos financieros provenientes de las exportaciones que, en virtud de su productividad, se habían transformado en el sector de la economía con capacidad de generar un excedente de ingresos.

Las características principales del modelo de protección social que tradicionalmente se desarrolló se apoyaron en la adopción de un régimen basado en la acumulación surgida de la actividad industrial que le otorgaba una dinámica apoyada en el crecimiento sostenido del mercado interno.

En términos sociales, la integración de la población se promovía por medio de distintas formas de intervención estatal destinadas a mantener altos niveles de empleo e ingresos. En ese contexto, el rol productivo que ejercían los miembros del hogar económicamente activos implicaba niveles relativamente altos de retribución laboral, que generaban ingresos elevados y bajos niveles de precarización de las condiciones de trabajo.

Una primera observación, al analizar el desarrollo de la protección social en Argentina es que el principio de orientación que la inspiró ha sido la subsidiariedad. Es decir, que el Estado sólo interviene cuando fallan las instituciones más próximas al individuo: el mercado y la familia.

La segunda observación, es que desde sus inicios, el sistema de protección estuvo segmentado; por ello, tendió a privilegiar generalmente a los funcionarios y estableció un sistema múltiple de acceso y, 
consecuentemente, niveles de prestaciones en razón del status profesional, a través del fortalecimiento de los mecanismos de representación y prestación de servicios de bienestar de tipo corporativista.

En tercer lugar, el familiarismo de éste modelo de protección social, consistió en que éste estaba dirigido principalmente al varón cabeza de familia, y a través de éste, hacía descansar sobre la familia la responsabilidad principal de dispensar cobertura del riesgo y cuidados de bienestar a sus miembros en circunstancias de necesidad; una obligación que se establecía incluso a través de preceptos legales.

En esta lógica de la protección social el lugar que ocupaba el trabajador formal -varón cabeza de familia- en el mercado de trabajo reforzaba la autoridad de aquél y la centralidad de esta institución mercado laboral- en la arquitectura de la protección social.

Por estos motivos, el sistema de protección social antes que responder a los riesgos derivados del mercado de trabajo se estructuró para responder a los riesgos derivados de los fallos en el sistema familiar y a aquellas situaciones que correspondían a la imposibilidad física de incorporarse a aquel mercado invalidez, edad, etc.

En términos de modelos de desarrollo lo que implícitamente se asumió era que el proceso de modernización conduciría al país hacia el mundo industrial por lo que Argentina tendía a transitar desde una sociedad agraria, con familias extendidas, baja esperanza de vida al nacer y alta proporción de trabajadores de baja calificación, hacia otro tipo de sociedad, urbanizada, con envejecimiento de la población, donde el empleo formal y la unidad familiar biparental estable bajo el modelo breadwinner serían la norma.

La intervención estatal en política social estuvo pensada para enfrentar una serie de riesgos relativos a la protección de la tercera edad, a la calificación de sus migrantes rurales, a la creación de mecanismos de manutención de renta individual y familiar (especialmente en las etapas tempranas del ciclo familiar) y a la creación de sistemas de salud y protección sanitaria adecuados para la convivencia urbana (HUBER y STEPHENS, 2005).

Si bien desde mediados de los años setenta, el modelo comenzó su transformación, no fue sino hasta fines de los años ochenta cuando la hiperinflación y la parálisis institucional brindaron inigualables condiciones para la adopción de un nuevo paradigma productivo. En efecto, los procesos hiperinflacionarios de 1989 y 1990 provocaron un deterioro en los sectores más bajos de la sociedad dando inicio al proceso de empobrecimiento de los sectores medios quienes brindaron una amplia aceptación a los postulados neoliberales con la esperanza de recuperar su situación anterior.

Bajo el proceso conocido como "Reforma del Estado" el gobierno promovió un conjunto de decretos que dieron lugar a la privatización de empresas estatales, la capitalización de créditos por parte de los acreedores del Estado, el despido de trabajadores como condición para las privatizaciones, la ejecución de los contratos de todo ente en que el Estado Nacional tuviera participación total o mayoritaria y la desregulación de las empresas privadas.

Al mismo tiempo se produjo una apertura de la economía y las políticas económicas se orientaron a conseguir la estabilidad de las cuentas externas y el saneamiento monetario. Para lograr este último objetivo, en 1991, Argentina impulsó un sistema de paridad cambiaria con el dólar conocido como Plan de Convertibilidad.

Siguiendo la interpretación prevaleciente de los organismos internacionales que se basada en la teoría neoclásica, las reformas económicas puestas en marcha en la Argentina reforzarían al mercado como asignador de recursos y eliminarían aquellas distorsiones que afectaban negativamente la demanda laboral ${ }^{1}$.

Las expectativas eran que 'las reformas incidirían en un aumento del empleo'. Este fue el 'consenso que desde Washington existía' sobre los efectos de la globalización para el empleo en los países del "Tercer 
Mundo" y específicamente de América Latina (Banco Mundial, 1995) y desde el cual, se concluyó que los procesos de la globalización generan costos y beneficios, y que los segundos superan a los primeros si los países adoptan políticas adecuadas².

Ese conjunto de políticas produjo un impacto en toda la estructura social de Argentina y definió una nueva matriz socioeconómica de alta vulnerabilidad. En síntesis, la ruptura del edificio de la protección social basado en el empleo y los ingresos por medio del proceso de creciente precarización del empleo se consolidó con la transformación del modelo de organización económica y social que se impuso en el país y en gran parte del mundo y que se centró en una transferencia de poder y recursos del Estado al sector privado.

Junto con el avance de políticas tendientes hacia la apertura del mercado por medio de disminuir la intervención estatal, se impulsó la transferencia de recursos al interior del aparato estatal con el objetivo de disminuir la relevancia del gobierno central e incrementar la de los gobiernos provinciales y municipales dentro de un proceso denominado descentralización.

Ésta descentralización, impulsada a partir de la década de 1990, se apoyó en la premisa de transferir la toma de decisiones y los beneficios de las políticas a los ciudadanos ya que se partía de la hipótesis que así se contribuiría al crecimiento y desarrollo de procesos democráticos sostenibles dando lugar al desarrollo de nuevas habilidades y capacidades municipales para la provisión de políticas públicas más acordes a las necesidades locales.

La observación en este sentido es que los municipios que ejecutaron programas descentralizados tuvieron mayor capacidad de gasto y autonomía para aplicar estos recursos en su territorio. Por otra parte, el carácter provisorio de estos programas (con una duración promedio de 2 años) y los requisitos de contraparte para ser municipio elegible (por ejemplo, gastos corrientes de los nuevos servicios o continuidad), motivaron que los municipios medianos y grandes hayan sido los principales ejecutores de estos programas.

Asimismo, la focalización, se instituyó como el otro cambio significativo en el marco de las reformas del estado. Por ello, más que propiciar nuevas inversiones para la expansión y mejoramiento de la calidad de los servicios en los sectores de salud, educación, vivienda, agua potable y saneamiento, cultura y recreación, y deporte, los recursos públicos estatales debían reducirse y orientarse hacia los sectores sociales que no disponían de los recursos para acceder a la satisfacción de estas necesidades a través del mercado.

Emergieron iniciativas vinculadas a áreas de identificación de beneficiarios, monitoreo y evaluación de resultados e impactos, proyectos en las áreas de infancia y tercera edad, y asistencia financiera para el desarrollo de programas alimentario-nutricionales.

Así, con la transferencia de gran parte de la responsabilidad de lo social a provincias y municipios, el estado nacional debía construirse un nuevo papel que se centró en reducir las diferencias que la aplicación de políticas universales no había corregido: los barrios y localidades sin servicios adecuados de salud, educación y atención a niños pequeños y ancianos.

Finalmente, el último elemento diferencial resultó del surgimiento de la heterogeneidad de la pobreza en los años 90 que fue, en parte, el resultado de la segmentación de los sectores medios que habían ocupado el centro de la estructura social y fueron los mayores beneficiarios de la educación pública y del empleo formal. Estos sectores respondieron a la caída en la inversión pública en educación de inicios de los años ochenta y a una renovada apelación a la diferenciación social centrada en nuevos consumos privados de servicios, abandonando la escuela pública y trasladando a sus hijos a los establecimientos privados.

Con el abandono del empleo y los ingresos, el efecto en la pobreza y la indigencia creció y se observó un proceso creciente de expansión de la desocupación y de la subocupación; de caída de los 
salarios; de deterioro de las condiciones de empleo de los que trabajaban y en consecuencia; de mayor pobreza.

Aquellos que sufrían estos cambios volvían a demandar atención del sector público para acceder a la educación, a la salud, a la vivienda y a los servicios que les habían quedado vedados. No obstante, la demanda de vivienda estuvo segmentada, prevaleciendo el crédito privado para un conjunto minoritario de la población, ya que se estableció un vínculo bancario entre formalidad laboral y acceso al crédito. Por otra parte, los fondos públicos destinados a la construcción de vivienda social (FONAVI), quedaron recortados por ley permitiendo a cada jurisdicción la posibilidad de su aplicación a gastos corrientes (Del Valle, 2006: 75).

La caída en el crecimiento económico entre 1998 y 2002, sumada al aumento del desempleo desde 1992 y la precarización del empleo a lo largo de todo el período, dieron por resultado un proceso de creciente fragmentación social que no encontró respuesta por parte del Estado sino hasta la crisis de 2001.

A partir de allí, se eliminaron gran parte de los programas nacionales que funcionaban descoordinadamente y se concentró el financiamiento en las áreas de alimentación, nutrición, salud (provisión de medicamentos, vacunas, otros insumos y leche fortificada) y, en programas de ingresos condicionados; en un primer momento orientados hacia la inserción laboral (Plan Jefes de Hogar) y, posteriormente hacia la gestión de riesgos y disminución del ciclo de reproducción de la pobreza (Plan Familias y Asignación Universal por hijo).

\section{Las nuevas transformaciones de la protección social}

\section{El sistema contributivo de previsión social}

El sistema previsional en Argentina se encuentra fragmentado y coexisten alrededor de 130 regímenes previsionales paralelos, entre los que se cuentan trece cajas de Jubilaciones y Pensiones Provinciales y veintiséis municipales, cajas para profesionales y otras cajas y regímenes complementarios (entes autárquicos especializados). Sin embargo, el SIPA es sin lugar a dudas el régimen previsional más importante, alcanzando a casi el 64\% de la población beneficiaria - Cuadro 1.

Cuadro 1: Número de beneficiarios según tipo de aportante al sistema previsional a diciembre del 2014

\begin{tabular}{c|c}
\hline Sistema Previsional & Beneficiarios \\
\hline SIPA & 7.286 .368 \\
\hline Autónomos & 357.083 \\
\hline Monotributo & 1.557 .661 \\
\hline Trabajo domestico $^{3}$ & 369.583 \\
\hline Otros regímenes $^{3}$ & 1.827 .762 \\
\hline Total & 11.398 .457 \\
\hline
\end{tabular}

Fuente: elaboración propia según datos del Ministerio de Trabajo, Empleo y Seguridad Social 


\section{4}

Gráfico1: Distribución de beneficiarios según tipo de aportante. Diciembre de 2014

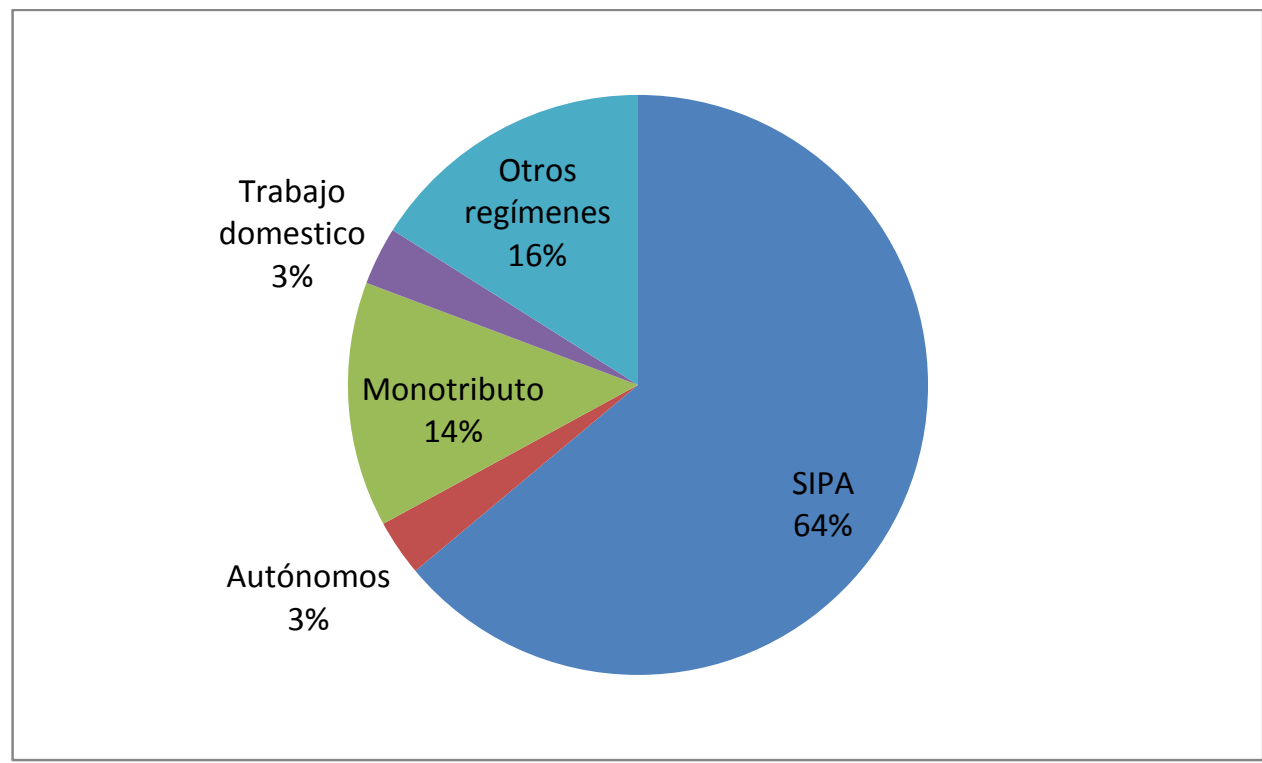

Fuente: elaboración propia según datos del Ministerio de Trabajo, Empleo y Seguridad Social

En este contexto, se puede afirmar que si la transformación operada durante los años 90 mercadocéntrica- se centró en el mercado como fuente principal de protección social; a partir de 2003 se inició un proceso de reestructuración de la protección social donde el Estado ocupó un nuevo rol. Algunos de los aspectos más significativos del modelo emergente de protección social en Argentina son: el proceso de re-estatización de los fondos de pensiones, el fortalecimiento y el creciente protagonismo de las áreas del gobierno nacional en tanto rectoras de los sistemas de salud y educación, la unificación de los programas de combate a la pobreza y la tendencia a la universalización de la seguridad social a través de instrumentos que combinan criterios contributivos y no contributivos.

Un aspecto de las transformaciones está vinculado al sistema de previsión social en tres aspectos importantes: aumento en los beneficios previsionales, inclusión de pensionados y reformas en su institucionalidad.

Tres son los momentos en los que se desarrolla esa transformación. En una primera instancia, entre enero de 2005 y abril de 2007 se constituye el Plan de Inclusión Previsional, cuyo objetivo era incorporar al sistema previsional a los adultos mayores que no tenían los aportes -contribucionesobligatorias al sistema de previsión pero que se encontraban en edad de jubilarse.

El principal instrumento a través del cual se implementó el Plan de Inclusión Previsional fue el artículo 6 de la Ley 25.994, y el Decreto 1454/05, el cual reglamentó la Ley 24.476 y permitió que los autónomos con problemas de regularización de aportes, se puedan inscribir en un plan de facilidades hasta el 30 de abril de 2007 para acceder al beneficio previsional, permitiendo el descuento de la deuda de la prestación mensual en hasta 60 cuotas.

La incorporación masiva de personas que no cumplían con los requisitos previsionales y las jubilaciones anticipadas para personas desempleadas con aportes incompletos, por su magnitud, ampliaron la cobertura previsional de la población en más del 60\% (Gráfico 1). 
Gráfico 2: Evolución de la Tasa de cobertura del sistema de previsión social 2001-2010

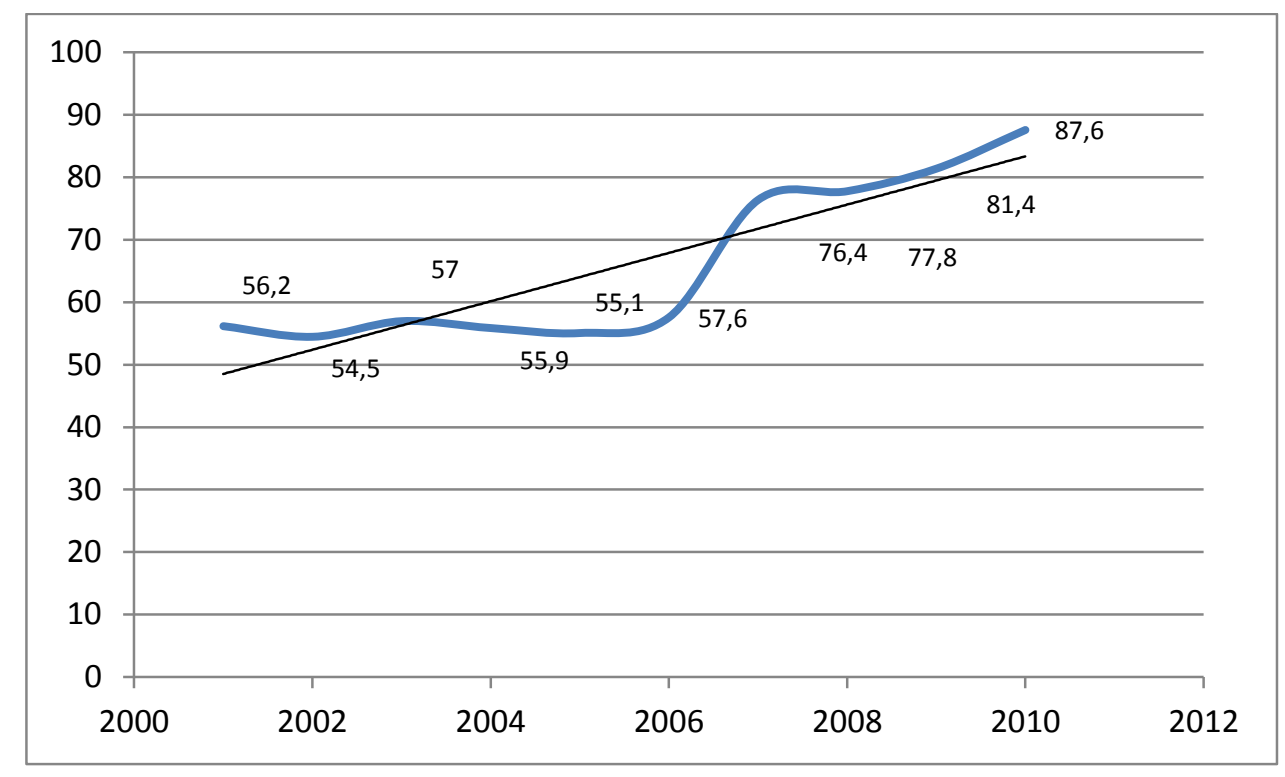

Al mismo tiempo, la obtención de la jubilación o pensión además del haber previsional, permite el acceso a la cobertura médica del Instituto Nacional de Servicios Sociales para Jubilados y Pensionados (INSSJP), y el derecho a recibir las asignaciones familiares correspondientes.

El segundo momento de esta transformación se produjo en marzo de 2007 con la aprobación en de la Ley $N^{\circ} 26.222$ que otorgó la opción a regresar voluntariamente al sistema de reparto estatal a los trabajadores que se encontraban bajo el régimen de capitalización, a la vez obligó el traspaso para quienes lo quisieran, a la vez que estableció como obligatorio el retorno al reparto estatal a quienes tenían pocos fondos acumulados.

Por último, en una tercera etapa, en octubre de 2008 se produjo una reforma estructural del sistema previsional -Ley $\mathrm{N}^{\circ}$ 26.425- al pasar del Sistema Integral de Jubilaciones y Pensiones al Sistema Integral Previsional Argentino (SIPA) por lo que todos los fondos de pensiones y jubilaciones pasaron a ser gestionados nuevamente por el Estado por lo que puso fin al sistema de capitalización individual.

El componente de Jubilaciones y pensiones junto con las asignaciones familiares y el seguro de desempleo son históricamente beneficios contributivos; sin embargo, las transformaciones arriba descriptas implicaron que junto a los ' 3 millones de beneficiarios - contributivos - accedieran al beneficio 2,4 millones de personas por medio del Plan de inclusión previsional' (BERTRANOU, 2010: 20-21)4.

Por último, en agosto del 2014 en la cual se establece que

Los trabajadores autónomos inscriptos o no en el Sistema Integrado Previsional Argentino (SIPA), y los sujetos adheridos al Régimen Simplificado para Pequeños Contribuyentes (RS), (...), que hayan cumplido a la fecha o cumplan la edad jubilatoria prevista en el artículo 19 de la ley 24.241 dentro del plazo de dos (2) años desde la vigencia de la presente, podrán regularizar sus deudas previsionales conforme el régimen especial establecido en la presente ley.

Es necesario destacar que actualmente la cobertura previsional en el país de la población mayor de 65 años llega al $94.6 \%$ según los últimos datos emitidos por ANSES. 
No obstante, existe en este esquema la cuestión referida a los montos que perciben los beneficiarios. En efecto, la mayor parte percibe el haber jubilatorio mínimo y éste, resulta insuficiente para cubrir las necesidades básicas de este sector.

En relación a las asignaciones familiares ${ }^{5}$ que son otro de los componentes contributivos del sistema de previsión social, desde 1957 éstas transferencias están dirigidas a menores de 18 años cuyos padres sean asalariados formales.

Durante la década de 1990 éstas prestaciones fueron focalizadas hacia los asalariados registrados de ingresos bajos y medios y, al mismo tiempo se redujo la alícuota que el empleador debía pagar para su financiamiento. En 2009 por medio del Decreto 1602/10 se produjo una profunda transformación de este componente ya que se expandió este beneficio a las familias de la economía informal por medio de la Asignación Universal por Hijo.

Las asignaciones familiares son percibidas por los asalariados del sector privado, beneficiarios del seguro de riesgos de trabajo y del seguro de desempleo, beneficiarios del Sistema Previsional y de las pensiones no contributivas. Estás comprenden diversos tipos de beneficios (nacimiento, adopción, maternidad, matrimonio, hijos, hijos discapacitados, escolaridad, escolaridad por hijo con discapacidad) y el monto de las mismas varía conforme los ingresos del asalariado.

Por último, el seguro de desempleo ${ }^{6}$ se trata de otro componente contributivo que cubre a aquellos asalariados formales que son despedidos (Ley $\mathrm{N}^{\circ} 24.013$ ). Esta protección comprende una prestación económica, la prestación médico asistencial, el pago de asignaciones familiares y el cómputo del período de las prestaciones a los efectos previsionales. Su monto corresponde al $50 \%$ de la mejor remuneración en los seis meses anteriores al despido, no pudiendo ser inferior a los $\$ 250$ (equivalente a 62,5 dólares) ni superior a $\$ 400$ (100 dólares) y su percepción es de hasta un año.

En este sentido, si consideramos la estructura ocupacional de la Argentina podemos observar que ambos rubros - Asignaciones y seguro de desempleo - solamente alcanza a los asalariados formales del sector privado - 38,15\% del total de la fuerza de trabajo activa; mientras que el $29,75 \%$ de la misma queda fuera de estos beneficios.

Gráfico 3: Distribución de la ocupación total - 2 trimestre 2010

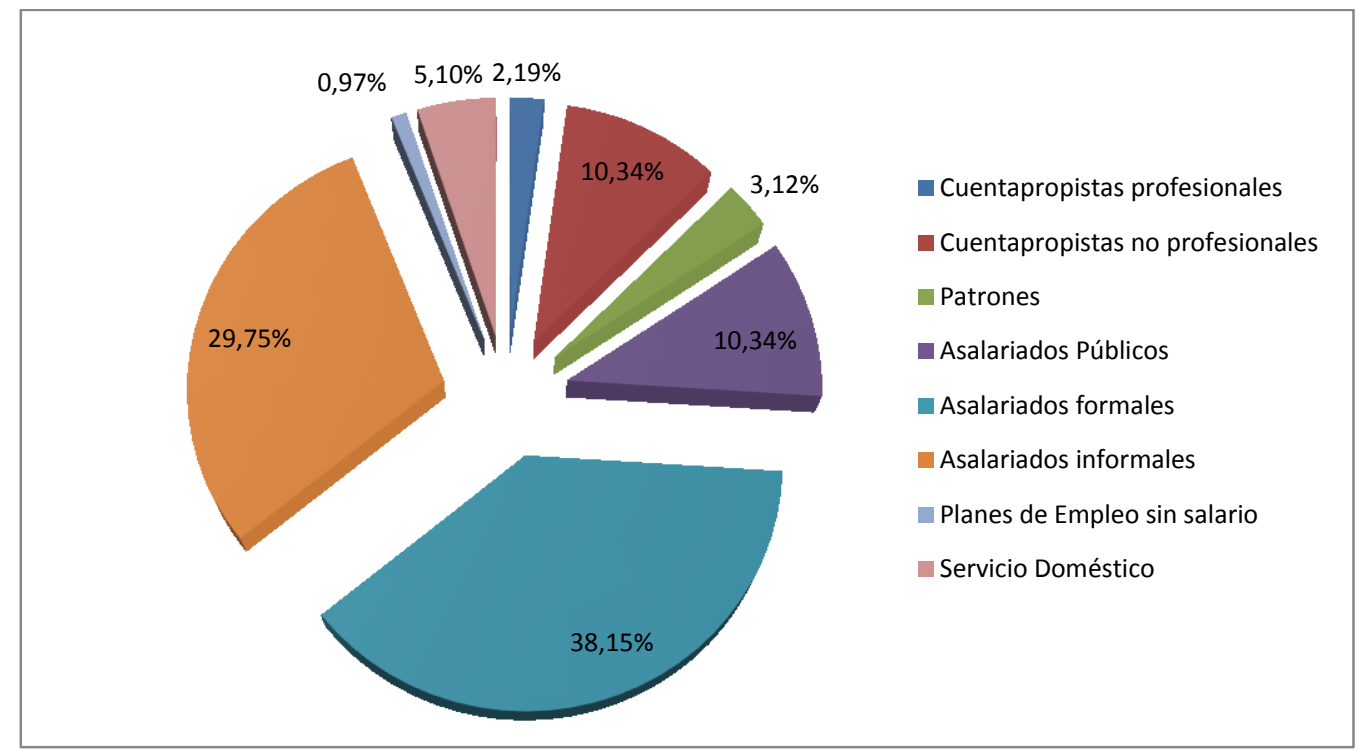


Esto se debe a que persiste la fuerte segmentación en el mercado laboral argentino donde poco más de la mitad de los trabajadores tienen un empleo formal, ya sea como asalariado privado en relación de dependencia, empleado público, trabajador independiente con trabajadores a cargo (empleador) o como cuentapropista profesional. Un $37.8 \%$ de los ocupados tiene empleos informales y un $7.4 \%$ de la población está desocupada; por lo tanto un $45.2 \%$ de la población económicamente activa, es decir casi la mitad de esta población no accede a la estructura de la seguridad social.

\section{El sistema no contributivo de previsión social}

Los beneficios no contributivos del sistema de previsión social en Argentina son: las pensiones no contributivas y la asignación universal por hijo y el PROGRESAR ${ }^{7}$. El primero de éstos beneficios está orientado hacia distintos grupos etarios aunque fundamentalmente alcanzan a mayores de 70 años, madres con más de siete hijos y personas con discapacidad que se encuentran en situación de vulnerabilidad social y que no realizan aportes contributivos y su carácter es vitalicio, en tanto se mantengan las condiciones que dieron lugar a su otorgamiento. Entre los beneficios de las pensiones no contributivas se encuentra el acceso a la atención médica gratuita -para el beneficiario y su grupo familiarpor medio del Programa Federal de Salud (PROFE).

En el caso de las pensiones no contributivas, los montos mensuales que se perciben son variables y dependen de las condiciones socio-familiares del beneficiario. Por ejemplo, por discapacidad (147 dólares); madres de siete ó más hijos (209 dólares) y adultos mayores (148 dólares) (Bertranou; 2010: 20). Es importante destacar -cuadro 2- que desde el año 2003 se ha ampliado notablemente la cobertura que pasó de 340405 beneficiarios en 2003 a 930575 en 2009.

Cuadro 2: Evolución de los beneficiarios de pensiones no contributivas según tipo de pensión 2003-2010

\begin{tabular}{|c|c|c|c|c|}
\hline Año & Otros & $\begin{array}{c}\text { Madres } \\
\text { con } 7 \text { hijos }\end{array}$ & $\begin{array}{c}\text { Vejez } \\
\text { invalidez }\end{array}$ & Total \\
\hline 2003 & 162128 & 57522 & 120756 & 340405 \\
\hline 2004 & 159053 & 61650 & 131599 & 352301 \\
\hline 2005 & 154566 & 82778 & 190138 & 427482 \\
\hline 2006 & 155850 & 101151 & 231874 & 488875 \\
\hline 2007 & 154252 & 128332 & 282148 & 564731 \\
\hline 2008 & 148239 & 170072 & 334078 & 652389 \\
\hline 2009 & 140869 & 232753 & 439207 & 812829 \\
\hline $2010^{a}$ & 137782 & 140869 & 523499 & 930575 \\
\hline
\end{tabular}

El otro componente del sistema no contributivo es la ya citada Asignación Universal por Hijo (AUH). Creada en 2009, esta se incorporó al Régimen de Asignaciones Familiares establecido por la Ley $\mathrm{n}^{\circ}$ 24.714 como su tercer pilar ${ }^{8}$. El objetivo de la misma es atender la situación de aquellos menores pertenecientes a grupos familiares que no se encuentren amparados por el Régimen de Asignaciones Familiares instituido para los trabajadores formales. En este sentido, ésta asignación, implica un cambio importante en los programas de transferencias condicionadas por dos motivos: primero, porque rompe con la relación tradicional entre empleo y acceso a derechos sociales por lo que prima la condición de ciudadanía de sus receptores; en segundo término, porque el presupuesto para el pago de éstas asignaciones se encuentra financiado por la ANSES por lo que posee una independencia relativa respecto al ciclo económico. 
En concreto, la AUH consiste en una prestación equivalente a la que reciben los hijos de los trabajadores formales, los beneficiarios del seguro de desempleo o los jubilados y abarca a los hijos en edad escolar de los trabajadores desempleados e informales y a los hijos de los beneficiarios de otros planes asistenciales que fueron traspasados a la AUH que perciban un ingreso menor al salario mínimo, vital y móvil. Para recibir la asignación, el menor debe ser argentino, hijo de argentino nativo o por opción, naturalizado o residente con al menos tres años de residencia legal en el país. A su vez, se restringe la prestación hasta cinco menores por cada grupo familiar (es decir, hasta \$1.100 por hogar).

El monto mensual de la asignación es de aproximadamente 72 dólares mensuales por hijo y de 235 dólares en el caso de hijos discapacitados. En ambos casos es obligatorio que los titulares del beneficio acrediten el cumplimiento de los controles sanitarios y el plan de vacunación, en el caso de los niños menores de 5 años y, en el caso de los niños y adolescentes en edad escolar, es obligatoria la certificación de cumplimiento del ciclo lectivo escolar correspondiente ${ }^{9}$. Por último, desde 2011, las mujeres que transitan su tercer mes de embarazo, también pueden acceder a la Asignación por Embarazo para Protección Social siempre que cumplan con los requisitos generales para acceder a la AUH. Estas mujeres, pueden percibir el beneficio hasta el nacimiento o interrupción del mismo y, para percibirla es requisito fundamental que las embarazadas estén inscriptas en el Plan Nacer y cumplan con los controles de salud necesarios en cada etapa del embarazo.

Cuadro 3: Evolución de beneficiarios y población infantil cubierta por la Asignación universal por hijo.

\begin{tabular}{c|c|c|c}
\hline Periodo & Niños cubiertos & Titulares & $\begin{array}{c}\text { Relación } \\
\text { niños/titulares }\end{array}$ \\
\hline Nov-09 & 3.313 .115 & 1.841 .126 & 1,80 \\
\hline Dic-09 & 3.419 .227 & 1.801 .116 & 1,90 \\
\hline Ene-10 & 3.235 .422 & 1.677 .611 & 1,93 \\
\hline Feb-10 & 3.395 .344 & 1.768 .081 & 1,92 \\
\hline Mar-10 & 3.520 .387 & 1.813 .490 & 1,94 \\
\hline Abr-10 & 3.679 .798 & 1.921 .428 & 1,92 \\
\hline May-10 & 3.686 .894 & 1.928 .706 & 1,91 \\
\hline Jun-10 & 3.512 .806 & 1.862 .835 & 1,89 \\
\hline Jul-10 & 3.486 .025 & 1.847 .336 & 1,89 \\
\hline Ago-10 & 3.404 .909 & 1.813 .802 & 1,88 \\
\hline Sep-10 & 3.460 .583 & 1.826 .245 & 1,89 \\
\hline Oct-10 & 3.470 .759 & 1.836 .151 & 1,89 \\
\hline Nov-10 & 3.502 .886 & 1.855 .199 & 1,89 \\
\hline Dic-10 & 3.513 .064 & 1.860 .389 & 1,89 \\
\hline Ene-11 & 3.514 .600 & 1.861 .984 & 1,89 \\
\hline Feb-11 & 3.507 .988 & 1.860 .473 & 1,89 \\
\hline
\end{tabular}

Fuente: Elaboración propia según datos de la Sub-secretaria de Seg Social. MTEySS en base a ANSES.

A inicios de 2011, la cantidad de beneficiarios de este programa ascendía a los 3507988 niños, niñas y adolescentes - Cuadro 3 - 1860473 de hogares distribuidos en todo el país por lo que se estima que su cobertura es prácticamente universal dentro de la población objetivo del programa. Gasparini y Cruces (2010) también concuerdan sobre la alta cobertura de la AUH.

En efecto, el 51\% de los niños, niñas y adolescentes cubiertos por la AUH no habían recibido nunca antes ninguna ayuda social en forma de transferencia de dinero (MTEySS, 2009). Si se considera que además de la $A \cup H$, habría 7,5 millones de niños con algún esquema de seguridad social, la cobertura actual brindada a los niños, niñas y adolescentes supera el $91 \%$ de la población menor de edad, considerando tanto los componentes contributivos como los no contributivos de la previsión social. 
Respecto a la alta cobertura de la población objetivo del programa, Bertranou (2010) sostiene que aproximadamente el $70 \%$ de los niños y adolescentes que la reciben se ubican en los dos primeros deciles del ingreso per cápita familiar y el $60 \%$ son pobres.

En este sentido, la AUH ha tenido un impacto positivo sobre los indicadores sociales ya que transfiere ingresos directamente hacia los hogares. Según proyecciones de ANSES difundidas en mayo de 2010, la AUH en su alcance teórico de 4,9 millones de niño, niñas y adolescentes impactaría en la tasa de pobreza de forma que esta pasaría del $9,1 \%$ al $6,4 \%$, lo cual supone una reducción del $35 \%$. A su vez, la tasa de indigencia pasaría del 3\% al 1,4\%, lo cual supondría una reducción del 53\% de la tasa y de 581 menores de 18 años que superarían dicha situación (ROCA, 2010).

Siguiendo lo señalado por Gasparini y Cruces (2010), y aún con otras fuentes (no oficiales) para medir la situación social, la universalización de la ayuda estatal por hijo implicará un impacto sustancial sobre la pobreza y la desigualdad de ingresos. Por ejemplo, Roca concluye que con la AUH:

... La incidencia de la pobreza cae un $21,9 \%$. Esto significa que más de 700.000 menores de 18 años salen de la pobreza. Por su parte, el porcentaje de hogares indigentes se reduce un $42,3 \%$, lo que equivale a que más de 400.000 menores dejen de ser indigentes. La desigualdad se reduce un $20 \%$ (medida como el cociente de los ingresos del primer y décimo decil)... (ROCA, 2010: 43)

EI PROGRESAR ha sido creado a inicios del año 2014 por el Gobierno Nacional mediante el decreto del Poder Ejecutivo Nacional № 84/2014. Este programa promueve que los jóvenes inicien o completen sus estudios y/o formación para el trabajo en cualquier nivel educativo y apunta a los jóvenes de entre 18 y 24 años, que no trabajan, trabajan informalmente o tienen un salario menor al mínimo vital y móvil y su grupo familiar posee iguales condiciones. Consiste en una transferencia de ingreso mensual, de la cual el $80 \%$ se percibe directamente y un $20 \%$ conforme las/os jóvenes acrediten, mediante certificación expedida por el establecimiento educativo o centro de salud correspondiente, que se encuentran estudiando o realizando una formación laboral, y que están inscriptos en el Plan SUMAR de salud y cumplen con los controles médicos. Además, el programa brinda cuidado de los hijos a cargo, cuando así se lo requiera.

La medida es financiada mediante el tesoro nacional y son más de 10 mil millones de pesos que se invertirán con el objetivo de alcanzar a 1,5 millones de jóvenes, es decir, al 30\% de los 4 millones de jóvenes de 18 a 24 años de Argentina. El programa depende de la Administración Nacional de la Seguridad Social (ANSES) y se ha creado un comité ejecutivo integrado por diversos organismos de la Administración Pública Nacional con competencias en la materia con la finalidad de contribuir al logro de los objetivos que tiene el PROGRESAR.

El programa ha visto modificadas sus características fundamentales en cuanto a los montos y cada titular del programa pasó de percibir 68 dólares a percibir más de 100 dólares. Por otra parte, también flexibilizó algunas de sus condicionalidades. Aumentó el ingreso tope del titular y su familia para acceder al derecho, el cual variará de un salario mínimo, vital y móvil tres salarios mínimos, es decir, de 530 dólares mensuales a 1589 dólares mensuales. Asimismo, se reconocerá como grupo familiar autónomo a los/as jóvenes con hijos y a aquellos que trabajen en casas particulares ya que, de esta manera, se les facilitará el acceso. Por otra parte, también se planteó una simplificación del control de regularidad escolar y salud, ya que ahora los estudiantes secundarios y terciarios deberán presentar el certificado de alumno regular 2 veces al año (antes eran 3 ) y los universitarios acreditado por la Universidad en forma electrónica. En cuanto al certificado de sanidad, se establece la inscripción obligatoria al programa SUMAR.

Esta política se articula con un conjunto de otras acciones a favor de la infancia, adolescencia y juventud que en los últimos años se vienen implementando en el país, las cuales están configurando un nuevo paradigma, el de la "protección ampliada" de la infancia, adolescencia y juventud (MAZZOLA, 2012). Este paradigma se abre paso en la convivencia con otros de antaño y tiene desafíos que son centrales en la profundización de una agenda distributiva. 


\section{Programas de Transferencias Monetarias}

Los programas de transferencias monetarias, sean en la modalidad de workfare con contraprestación laboral o bajo la forma de condicionalidad, por ejemplo cumplir con la terminalidad educativa se desarrollan en Argentina desde la década de 1990 y llegaron a su mayor cobertura luego de la crisis de 2001 con la implementación del Plan Jefes y Jefas de Hogar Desocupados (PJJHD).

Entre el 2003 y hasta el momento de la implementación universal por hijo, coexistían el citado PJJDHD; el Seguro de Capacitación y Empleo - ambos bajo la órbita del Ministerio de Trabajo, Empleo y Seg. Social - e implicaban una contraprestación y el Programa Familias por la inclusión, creado en 2003, y ejecutado por el Ministerio de Desarrollo Social que implicaba la condición de vacunación y asistencia escolar de los menores.

Para el año 2011, el PJJHD ya no se encuentra incorporado al presupuesto mientras que el Programa Familia tiene un espacio residua ${ }^{10}$ por lo que tan solo se mantiene el Seguro de Capacitación Laboral y Empleo (SCyE) que gradualmente ha ido incrementando su participación en el presupuesto público. Éste programa otorga un subsidio (prestación mensual equivalente a 56,25 dólares- durante un período máximo de 24 meses) y ofrece otros servicios de apoyo a la inserción laboral (orientación y asistencia en la búsqueda de empleo, intermediación laboral, formación básica y profesional, entrenamiento para el trabajo y/o asistencia técnica para la formulación de proyectos de autoempleo). Debido a que éste seguro es incompatible con la Asignación universal por hijo, y los montos de la AUH son mayores que los de éste programa, la tendencia ha sido a que él mismo disminuya la cantidad de beneficiarios. No obstante, para 2012 se estima alcanzar una cobertura de 155.645 beneficiarios, más de un $50 \%$ a lo proyectado para 2011.

De todos modos, se espera que la cantidad de beneficiarios del SCyE vuelva a incrementarse como consecuencia del traspaso de los beneficiarios del Programa de Empleo Comunitario (PEC) que tiene 300.000 beneficiarios -trabajadores desocupados- que perciben 37,5 dólares mensuales y que se encuentra actualmente en proceso de disolución.

Asimismo, bajo el MTEySS se encuentra el Programa Acciones de Capacitación Laboral, el cual pasó de \$631 millones en 2011 a \$1.027 millones para el 2012. Este programa incluye el subprograma Plan Jóvenes con Más y Mejor Trabajo (financiado por el Préstamo BIRF 7474-AR), y dirigido a jóvenes de entre 18 y 24 años de edad, desocupados y con estudios formales incompletos. Las acciones del programa están orientadas principalmente a lograr la terminalidad educativa y formación profesional de estos jóvenes pero también de los beneficiarios de los programas de Empleo Comunitario y del Seguro de Capacitación y Empleo ya citado. En el presupuesto 2012, la meta prevista es asistir a 133.000 jóvenes.

Dentro de las Acciones de Empleo que para 2012 tienen previsto un presupuesto de $\$ 756,7$ el principal componente es el Plan de Mantenimiento del Empleo Privado, que tiene como objetivo sostener el empleo en sectores económicos que tienen dificultades. El programa otorga una suma remunerativa de hasta $\$ 600$ mensuales y por el plazo de hasta 12 meses. Se brinda asistencia financiera a 2.417 empresas en el país para completar la remuneración básica del trabajador.

Desde el Ministerio de Desarrollo social se ejecuta desde agosto de 2009 el Programa de Ingreso Social con Trabajo (Argentina Trabaja). Las cooperativas creadas, tienen como finalidad realizar trabajos comunales relativamente simples, de pequeña y mediana dimensión (reparación y ampliación de escuelas, arreglos de baches, instalación de cloacas, mejora y mantenimiento de espacios públicos, plazas, etc.). Se estimó en el momento de la creación que cada cooperativa iba a reunir entre 50 y 70 personas. Esta iniciativa se planteó como objetivo principal la "promoción del desarrollo económico y la inclusión social, generando nuevos puestos de trabajo genuino, con igualdad de oportunidades, fundado en el trabajo organizado y comunitario, incentivando e impulsando la formación de organizaciones sociales de trabajadores" (Res. №3182, Ministerio de Desarrollo Social) ${ }^{11}$. 
Por otra parte, en lugar de distribuir los excedentes a los asociados (un adelanto mensual del retorno como participación económica de los socios y al final del año una parte del excedente en función del trabajo realizado), entregarían de antemano una suma de dinero mensual en concepto de sueldo. Para poder acceder al mismo, los socios de estas cooperativas deben anotarse como monotributista social y hacer el aporte correspondiente, con lo cual el "sueldo" neto facturado sería de 292 dólares. Los trabajadores son inscriptos como "efectores sociales", por lo que acceden a la jubilación y a la obra social a través del Monotributo Social. En condición de monotributistas sociales, los cooperativistas tienen acceso a la Asignación Universal por Hijo. A cambio, deben cumplir con una jornada laboral de 40 horas semanales (cinco horas destinadas a capacitación), como miembros de cooperativas de trabajo. Las acciones del programa están dirigidas a personas sin ingresos formales en el grupo familiar y sin acceso a otras prestaciones, pensiones, jubilaciones nacionales o planes sociales, a excepción del Plan Nacional de Seguridad Alimentaria.

A diferencia de otros programas, en éste se destaca el papel que poseen los municipios (y en algunos casos a las provincias) en la gestión cotidiana del mismo. En efecto, el gobierno nacional por intermedio del ministerio de Planificación e Infraestructura Social realiza los aportes al municipio para gestionar la actividad, comprar los insumos, herramientas de trabajo, dispositivos de seguridad, ropa de trabajo, etc.

Estas cooperativas de trabajo tienen algunas especificidades respecto a las tradicionales: en primer lugar, la iniciativa proviene del estado y en lugar de la libre adhesión, los socios son invitados o seleccionados por las autoridades municipales o los responsables de movimientos sociales; en segundo término, la cooperativa tiene un presidente, un secretario, un tesorero y un coordinador general, designado en acuerdo con el MDS y las autoridades locales, que organiza las tareas de los miembros, que normalmente hubieran estado a cargo de los empleados municipales; por último, en lugar del Consejo de Administración, son las autoridades municipales o las agrupaciones sociales quienes asumen la tarea de organizar las cooperativas, condicionando las decisiones a tomar, limitando la autonomía, la independencia y el control democrático de los socios.

Desde su inicio el programa tuvo un crecimiento sostenido - Cuadro 4 - y pasó a proveer ingresos en Junio de 2011 a 157.745 beneficiarios.

Cuadro 4: Cantidad de cooperativas ${ }^{12}$ de trabajo del programa Argentina Trabaja según provincia (2013)

\begin{tabular}{c|c|c|c}
\hline PROVINCIA & $\begin{array}{c}\text { TOTAL } \\
\text { COOPERATIVAS ACTIVAS }\end{array}$ & PROVINCIA & $\begin{array}{c}\text { TOTAL } \\
\text { COOPERATIVAS ACTIVAS }\end{array}$ \\
\hline BUENOS AIRES & 4115 & MENDOZA & 81 \\
\hline CATAMARCA & 69 & MISIONES & 88 \\
\hline CHACO & 172 & RIO NEGRO & 34 \\
\hline CORDOBA & 33 & SALTA & 59 \\
\hline CORRIENTES & 104 & SAN JUAN & 65 \\
\hline ENTRE RIOS & 153 & SANTA FE & 42 \\
\hline FORMOSA & 26 & SAN LUIS & 11 \\
\hline JUJUY & 68 & SANTIAGO DEL ESTERO & 98 \\
\hline LA RIOJA & 52 & TUCUMAN & 525 \\
\hline
\end{tabular}

Fuente: Ministerio de Desarrollo Social de Nación.

Bertolini señala que éstas cooperativas de trabajo no respetan la concepción de la Alianza Cooperativa Internacional que en el año 1995 las planteó como:

una asociación autónoma de personas que se han unido voluntariamente para hacer frente a sus necesidades y aspiraciones económicas, sociales y culturales 
comunes por medio de una empresa de propiedad conjunta y democráticamente controlada (BERTOLINI, 2009).

Asimismo, pone en duda la capacidad de generación de trabajo genuino de estas cooperativas, así como también el respeto de algunos de los principios y valores del cooperativismo; como la autonomía, la independencia y el control democrático, debido a que el programa que las fomenta tiene una duración limitada, las tareas que deben realizar son impuestas por el Estado y muchas veces no están gestionadas por los propios trabajadores.

En este sentido, se ha planteado que "la imposición por parte del Estado de una determinada forma de asociación para recibir un beneficio asistencial es contraria al propio espíritu cooperativo" (LO VUOLO, $2010 ; 14)$. El autor postula que uno de los problemas centrales a los que se enfrenta este programa tiene que ver, por un lado con "la discrecionalidad aplicada en la distribución de sus beneficios y su consiguiente uso como instrumento para conseguir lealtades político-partidarias". Sin embargo para el autor, el problema central reside en la continuidad de un modo estático de regulación de la cuestión social. Por otra parte, también señala que el programa se apoya en dos paradigmas de intervención en lo social, una "modernista-tecnocrática" y la otra "asistencial-represiva" ${ }^{13}$. Según el autor esta regulación estática de la cuestión social ha demostrado ser inadecuada e ineficaz ya que el objetivo de la misma

no es la erradicación de las expresiones más acuciantes (pobreza, desempleo, lazos precarios en materia laboral y relacional, etc.), sino administrar estos problemas de forma tal de no alterar el funcionamiento considerado correcto y normal de la sociedad y la economía. Es un modo de gestión que realiza el Estado de la cuestión social con el objetivo principal de subordinar la atención de los problemas sociales a la administración general del gobierno (LO VUOLO, 2010: 4).

Estas críticas al programa aportan insumos esenciales para repensar la política social en Argentina. Lo cierto es que en el año 2009 este programa absorbió un 18\% de los fondos del Ministerio de Desarrollo Social (1.500 millones de pesos) ascendiendo a 4.570 .95 millones de pesos para el 2012 alcanzando a cerca de 200.000 personas en todo el país (GOLBERT, 2012). Esto impacta positivamente en un núcleo potencial de alrededor de un millón de personas a lo largo del país quienes acceden a un ingreso fijo, obra social, seguro de accidentes, capacitación, escolaridad y especialmente, la propuesta de generar lazos laborales y de asociatividad. Es decir, los sectores más vulnerables de la población y excluidos del mercado de trabajo acceden a una nueva forma de reproducción de sus condiciones de existencia.

De acuerdo con la OIT el trabajo decente es "aquella ocupación productiva que es justamente remunerada y que se ejerce en condiciones de libertad, equidad, seguridad y respeto a la dignidad humana" (OIT, Levaggi, pág. 28). En este sentido, es sumamente discutible que esta política se puede denominar como una ampliación de ciudadanía. Se sigue planteando un trabajo para pobres hecho por pobres. Trabajo poco calificado y con una remuneración por debajo de la Canasta Básica Alimentaria. Por lo tanto no podemos incluir estas actividades dentro de la definición de la OIT.

\section{Conclusiones}

La construcción de una red universal de protección social, en Argentina, se encuentra actualmente frente al desafío de consolidar y ampliar su campo de acción y disminuir la estratificación de los servicios y beneficios. Esto se relaciona con el sistema establecido de protección social, que al haber sido diseñado en función del sector formal del empleo, excluye o brinda un acceso estratificado a sus beneficios a la mayor parte de la población. En este sentido, se torna difícil imaginar una política social sustentable sin mejorar las tasas de empleo y los niveles de ingresos de las familias pobres esto implica introducir modificaciones en la actual estructura distributiva del ingreso. 
Las alternativas descansan en un nuevo sistema fiscal más progresivo y eficiente, que provea de recursos al financiamiento de un sistema de política social que garantice los requerimientos alimentarios fundamentales para todas las familias. La focalización en este caso solo debería identificar a aquellos sectores ubicados en los primeros dos quintiles de la distribución debido a que por las características universales del gasto social y del sistema de seguridad social el efecto distributivo de las políticas focalizadas ha sido insignificante y no se ha orientado mayoritariamente hacia éstos sectores.

Mostajo (2000: 23) ha mostrado que a pesar del avance del gasto social focalizado, en el caso Argentino, esto no se tradujo en una distribución progresiva del ingreso por lo que "...la concentración de ingresos aumentó (a pesar del incremento del gasto social) y el estrato superior ganó participación en el ingreso total en desmedro de los estratos bajos...".

Esto se debe, entre otros factores, al peso de la seguridad social por sobre los demás componentes del gasto y se traduce en una dificultad para el desarrollo de políticas compensatorias sobretodo en períodos de crisis por lo que, el gasto focalizado tiende a disminuir su participación en estos escenarios. En principio,

...la consolidación de una red de protección social tiene que generar certidumbres, en el sentido de garantizar que habrá de sostenerse e incrementar su participación en el gasto durante períodos de contracción fiscal (dimensión pro cíclica) de tal modo que pueda funcionar con cierta independencia del crecimiento económico... (DEL VALLE, 2008: 89)

En síntesis, la debilidad fundamental del sistema radica en el hecho que al poseer un régimen de bienestar diseñado en función del sector formal del empleo, la red de protección social no alcanza para incluir a todos los grupos en situación de riesgo y, considerando que el monto de la transferencia es claramente insuficiente y se encuentra limitado a la obtención de un trabajo formal. Es por ello, que se puede afirmar que, en Argentina, estamos asistiendo a la consolidación de una red restringida de protección social que no alcanza a cubrir completamente a los sectores en situación de pobreza estructural.

Se puede afirmar que, en sentido estricto, a partir de 2002 existe una red restringida de protección social cuyos efectos sobre la distribución del ingreso son limitados debido a las características que posee el propio régimen de bienestar.

Éstas características son universalidad y estratificación de la salud y la educación y segmentación de la seguridad social; es decir, existe un sistema de protección social que se autofinancia con los aportes de los mismos trabajadores y que es administrado por medio de los sindicatos y el sistema de Seguridad social y, desde 1990 hasta la fecha se ha ido constituyendo un sistema que paso a definir un área específica, dentro de las políticas públicas y cuya características principal es la 'focalización'.

Es esperable que el desempleo, las dificultades de acceso a la salud y educación y el alto nivel de carencias corrientes que enfrenta la población de más bajos ingresos continúe atentando contra la formación de capital humano y la acumulación de otros activos que permitan a estas familias, a través de sus descendientes (intertemporalmente) salir de la pobreza y la indigencia aún en un contexto de crecimiento favorable ( $8 \%$ en promedio anual desde 2002 a la fecha), por lo que estos problemas continuarán siendo el núcleo de las demandas sociales y por tanto, estarán en el centro del diseño de las políticas.

Sin embargo, la ausencia de fondos incrementales para ampliar la red de asistencia, sujeta a ésta red al desenvolvimiento del ciclo económico; de allí que podemos afirmar que el bienestar general dependió y hasta la actualidad depende del ciclo económico antes que, de algún modelo de justicia social que funcione en la base de la gestión política con la premisa de asegurar un piso de derechos igual para todas y todos los ciudadanos. 
Como se indicó, las transformaciones del mercado de trabajo luego de las décadas de 1980 y 90 se caracterizan por el surgimiento del desempleo estructural, la precarización de las relaciones laborales, el crecimiento del sub-empleo y la consolidación de un mercado informal como elemento estructural de las relaciones económicas, por citar algunas.

A los cambios en el mercado laboral, las familias han tendido a responder incorporando aportantes (Del Valle, 2010) con lo que se modificó el sistema de aportante único. Al mismo tiempo se produjo la incorporación de la mujer al mercado laboral y cambios a nivel del tipo y composición de las unidades familiares - monoparentalidad, jefatura femenina, familias extendidas - (ARRAIGADA, 2004).

Esto implica asumir que, a partir de las transformaciones operadas en los 80 y 90, la distribución (según categorías sociales) de la cantidad y la calidad de los riesgos sociales ha cambiado. En este cambio han operado las decisiones que toman las personas en las esferas del mercado, de las familias y de las comunidades. Las formas en que la gente y las empresas compran y venden mercancías (trabajo, bienes y servicios), se localizan en el territorio y definen y legitiman arreglos familiares que también han sufrido transformaciones profundas con consecuencias en la distribución del riesgo entre clases, sexos, generaciones y poblaciones asentadas en diferentes territorios.

Por un lado, el modelo tradicional de familia nuclear biparental, encabezada por un padre proveedor, está cambiando aceleradamente, y las familias nucleares que corresponden al modelo tradicional, constituida por el padre y la madre e hijos y en la que la cónyuge realiza las tareas domésticas, ya no son la mayoría en América Latina (CEPAL, 2004; ARRIAGADA, 2004).

En segundo término, los cambios en la estructura familiar fueron concomitantes a la incorporación de la mujer a la fuerza de trabajo. Entre 1990 y 2002, por ejemplo, la tasa de participación femenina en zonas urbanas de América Latina aumentó del 37,9\% al 49,7\% (CEPAL, 2004). Casualmente, debido a que todavía la tasa de participación de la mujer es menor que la de los hombres y a la menor calidad de los empleos de las mujeres, la brecha contributiva existente en la región es significativa: 'solo el $19 \%$ de las mujeres de 15 a 64 años hace aportes al sistema de seguridad social en comparación con el 32\% en el caso de los hombres' (DEL VALLE, 2010: 104).

En tercer lugar, en Argentina la transición demográfica y el envejecimiento de la población influyen negativamente en el sistema de protección y, en particular, en la protección de la salud y de los ancianos. El aumento de la esperanza de vida se traduce en una mayor carga para los sistemas de pensiones, encarece la atención de la salud y modifica la relación de dependencia entre beneficiarios y contribuyentes.

En el marco de estas reflexiones es importante destacar que existen dificultades para reconocer estas nuevas estructuras y dinámicas de producción de riesgo por lo que habría que indagar si la estructura de protección social contribuye a acentuar los riesgos emergentes antes que a moderarlos.

La acentuación de los riesgos es resultado de que el sistema de protección se ha desarrollado para un modelo ideal de sociedad pero en la actualidad, este mismo sistema da lugar y alimenta el desarrollo de tres sociedades. Existe una sociedad mercantilizada donde por la vía privada-mercado- un sector de la población se abastece de los bienes y servicios que le proveen bienestar. Paralelamente, existe un subsistema de protección social para los trabajadores formales, en éste, los sindicatos y clases medias y mediobajas vulnerabilizadas se encuentran sujetas al deterioro en su calidad de vida por el debilitamiento de la capacidad protectora de los antiguos sistemas de prestaciones sociales. Por último, existe una sociedad excluida donde el principal mecanismo de acceso a recursos es el mercado informal que se combina con prestaciones y servicios sociales de carácter público.

El conjunto, nos permite vislumbrar el nacimiento de una nueva versión de lo que se puede rebautizar como la sociedad de los tres tercios. En efecto, la sociedad argentina que surgió de las transformaciones y reformas de las décadas de 1980 y 1990 se ha encontrado con la incapacidad del Estado para reestructurar su arquitectura de protección. En este sentido, la acción estatal tendió y tiende a sobre 
determinar las causas de intervención y acaban dando lugar a la emergencia de 'tres países', cada uno formas particulares de producir y reproducir riesgo y bienestar dentro de un mismo espacio territorial.

En este sentido, la actual disposición de prestaciones sociales mantiene y profundiza la estructura de riesgos sociales existente. Esta afirmación, implica asumir -al menos en parte- la hipótesis de Levy (2008) que afirma que la expansión de programas sociales no focalizados podría provocar un aumento de la informalidad económica ${ }^{14}$.

Ciertamente, los trabajadores insertos en el sector informal de la economía reciben, por su condición de excluidos o su calidad de desempleados, diversas formas de asistencia y protección social. En sí mismos, por ejemplo, los ingresos de transferencias condicionadas o los ingresos de actividades informales resultan insuficientes pero combinadas ambas fuentes de retribución sirven para garantizar una mano de obra 'económica' y dispuesta a trabajar en cualquier condición. Paradójicamente, esto puede ser interpretado, a diferencia del planteo de Levy (2008) como el equivalente de una subvención estatal a las empresas del sector informal. O por expresarlo en otros términos, como un mecanismo de intervención estatal que tiende a mercantilizar informalmente a la fuerza de trabajo.

Desde el punto de vista de la teoría social -aunque no de la teoría normativa- que la acción estatal se oriente o diga orientarse hacia la inclusión, no significa que la misma no cumpla una función en la base de persistencia de los procesos de exclusión y mantenimiento de un sector informal que, sin duda, representa una parte importante del proceso de acumulación de capital. En el plano material, la persistencia de la exclusión cuestiona la capacidad de las políticas sociales (incluyendo el sistema de protección social) como instrumentos eficaces en la disminución de los riesgos sociales y, consecuentemente, de los procesos de exclusión.

En el marco de un sistema de protección social dual, la presencia de programas y beneficios sociales de base no contributiva reducen los incentivos a la formalidad para empleadores. Al respecto, existe amplia evidencia empírica sobre cómo operan estos mecanismos y sobre sus resultados en el mercado de trabajo, por ejemplo, Galiani y Weinschelbaum (2007) muestran que los trabajadores secundarios en América Latina tienen una mayor propensión a la informalidad si los trabajadores primarios en el mismo hogar están cubiertos $^{15}$.

En realidad, la presencia de mecanismos de inclusión/exclusión se conjuga con la presencia de mecanismos de incentivos a la formalidad/informalidad en el mercado de trabajo. En este contexto, la cobertura parcial de los sistemas contributivos existentes y la expansión de los programas no contributivos reducen uno de los atractivos de un empleo "en blanco". Por lo que la pregunta que surge se vincula a la necesidad de avanzar hacia la conformación de un único sistema de ingreso universal a la niñez; a la vejez; etc.

Sin embargo, en el actual contexto, el sistema tradicional de protección social coexistirá con programas no contributivos de creciente cobertura. Un riesgo, sin embargo, es que la presencia de estos desincentivos resulte en el rechazo a medidas con impacto neto potencial positivo, y por ello será fundamental discutir estos problemas abiertamente. Aunque en la actualidad será necesario comenzar a diseñar alternativas de política que minimicen los conflictos de incentivos (a la informalidad, a la participación laboral, etc.).

\section{Referencia $^{16}$}

ACOSTA, Olga y Ramírez, J. (2004). “Las redes de protección social: modelo incompleto”. Unidad de Estudios Especiales. CEPALNaciones Unidas.

ARRIAGADA, Irma (2004). "Cambios y continuidades en las familias latinoamericanas. Efectos del descenso de la fecundidad" en La fecundidad en América Latina: ¿Transición o revolución? en Serie Seminarios y Conferencias № 36, CELADE, 2004. 
Asian Development Bank (2001). Social Protection Strategy. Disponible en: http://www.adb.org/Documents/Policies/Social Protection/social205.asp

BANCO MUNDIAL (2001). World social protection sector strategy: from safety net to springboard, Washington.

BERTOLINI, Gustavo (2009). Un primer abordaje del plan de ingreso social con trabajo. Más dudas que certezas. Buenos Aires, Fundación CIESO.

BERTRANOU, Fabio (coord.) (2010) Aportes para la construcción de un piso de protección social en Argentina: El caso de las asignaciones familiares, Oficina de la OIT en Argentina, Buenos Aires.

CEPAL - Comisión Económica para América Latina- (2004) Panorama social de América Latina, 2004 (LC/L.2220-P/E), Publicación de las Naciones Unidas, Santiago de Chile.

CETRÁNGOLO, Oscar; JIMÉNEZ, Juan Pablo; DEVOTO, Florencia y Vega, Daniel (2002). “Las finanzas públicas provinciales: situación actual y perspectivas", en Serie Estudios y Perspectivas, № 12, CEPAL, Buenos Aires.

CICHÓN, Michael; SCHOLZ, Wolfgang; MEERENDONK, Arthur van de; HAGEMEJER, Krzysztof; BERTRANOU, Fabio y PLAMONDON, Pierre (2004). Financing Social Protection, Quantitative Methods in Social Protection Series, Geneva, International Labour Office/International Social Security Association.

Del Valle, Alejandro (2001) Estrategias y Prácticas Sindicales: la reforma laboral en Argentina, Univ. De Barcelona, Barcelona. TESEO-UNICEF. Microfilm

DEL VALLE, Alejandro (2006), Y...¿por qué trabajar? La política Social en la Argentina Post-convertibilidad, en GIPSOC, Derechos sociales, Ciudadanía y Bienestar, EUDEM, Bs. As.

. (2008). Política social focalizada y construcción de una red social. Lecciones de la experiencia argentina. En Revista Estudios sociales Nro 32 Vol. XVI, División de Estudios Políticos- Centro de Investigación en Alimentación y Desarrollo, Universidad de Sonora, Hermosillo, AC, México.

(2010). Reformas estructurales, Mercado de trabajo y Protección social en América latina, en Portularia - Revista de Trabajo Social Nro. 1 Vol. X, Departamento de Trabajo Social y Sociología, Universidad de Huelva, España. Pag. 3-21.

ELÍAS, D. (2010). Seminario sobre el Sistema Previsional Argentino. Un modelo integrado de previsión social. Buenos Aires. Disponible en: http://www.asap.org.ar/images/stories/file/Encuentros/danielelias.pdf

FIELDS, G. (1994): Data for measuring poverty and inequality changes in the developing countries, Journal of Development Economics, vol. 44, $\mathrm{N}^{\circ} 1$, North-Holland Publishing Company, Amsterdam, Países Bajos.

FILGUEIRA, Fernando (2005). Welfare and Democracy in Latin America: The development, Crises and Aftermath of universal, Dual and exclusionary social States, UNRISD, Project on Social Policy and Democratization, Geneva, May.

FUNDACIÓN CIMIENTOS (2011). La educación argentina en números. Documento № 6: Actualización de datos estadísticos sobre la escolarización en Argentina. Abril, Buenos Aires.

GALIANI, S., and WEINSCHELBAUM, F. (2007). Modeling informality formally: Households and firms. Working Papers 47, CEDLAS, Universidad Nacional de La Plata, Marzo.

GASPARINI, Leonardo y CRUCES, Guillermo (2010). "Las asignaciones universales por hijo. Impacto, discusión y alternativas". Documento de Trabajo CEDLAS № 102, UNLP, La Plata.

GOLBERT, Laura (2012). ¿Piso o Sistema Integrado de Protección Social? Una Mirada desde la experiencia Argentina. Golbert, Roca Laura, Emilia Eugenia; Estela Lanari. Ministerio de Trabajo, Empleo y Seguridad Social.

GOJZMAN, D. (Coord.); CAJADE, Andrea; ESTIGARRIBIA, Maximiliano; KUNICA, Sebastián; y MAZZOLA, Roxana (2010). Hacia una Metodología para Orientadores que Trabajan con Jóvenes. Programa Fuerza Solidaria del Banco de la Provincia de Buenos Aires, Asociación Civil ETIS y Japanese International Cooperation Agency (JICA). Buenos Aires: Editorial EUDEBA.

GONZALO GONZÁLEZ, Bernardo (2001). La protección social: perspectiva histórica-crítica", Foro de Seguridad Social, Madrid.

HAGEMEJER, K (2001). Social Protection expediture and performance reviews, Ginebra, OIT.

HOLZMANN, Robert y JORGENSEN, Steen (2000). Manejo social del riesgo: un nuevo marco conceptual para la protección social y más allá, Banco Mundial, Washington, Serie de Documentos de Discusión sobre la Protección Social, núm. 6.

HUBER, Evelyn y STEPHEN, Johan (2005). "Successful Social Policy Regimes? Political Economy and the Structure of Social Policy in Argentina, Chile, Uruguay and Costa Rica." Paper presentado en la conferencia sobre Democratic governability in Latin America, Notre Dame, Octubre 6-7.

LEVY, S. (2008), Good Intentions, Bad Outcomes: Social Policy, Informality and Economic Growth in Mexico, Brookings Institution Press, Washington, D. C.

LO VUOLO, Rubén (2010) "El programa "Argentina Trabaja" y el modo estático de regulación de la cuestión social en el país", en Documentos de Trabajo del CIEPP N 75.

MACEIRA, Daniel (2008) "Sistema de salud en Argentina”, presentación, CIPPEC/CEDES, Buenos Aires.

MARCUS, R. (2004). "The Role of Cash Transfers in Tackling Childhood Poverty". CHIP Policy Briefing 2. Childhood Poverty Research and Policy Centre.

MAZZOLA, R. (2012). Nuevo Paradigma. La Asignación Universal por Hijo en la Argentina. Buenos Aires: Editorial Prometeo. MESA-LAGO, Carmelo (1989). Ascent to Bankruptcy, Pittsburgh: Univ. of Pittsburg Press.

Textos \& Contextos (Porto Alegre), v. 14, n. 2, p. 338 - 358, ago./dez. 2015 
MINISTERIO DE SALUD DE LA NACIÓN - MSA - (2008). Dirección de estadística y consulta en salud, “Consulta en Línea”. Disponible en: http://www.deis.gov.ar

MINISTERIO DE TRABAJO, EMPLEO Y SEGURIDAD SOCIAL (2009). "Impacto de la Asignación Universal por Hijo en la pobreza y el ingreso de los hogares (estimación al $2^{\circ}$ trimestre de 2009)", Buenos Aires.

MOSTAJO, Rosana (2000). “Gasto social y distribución del ingreso: caracterización e impacto redistributivo en países seleccionados de América Latina y el caribe", Serie Reformas Económicas, CEPAL (LC/L 1376).

NAVARRO, V. y QUIROGA, A. (2003) La protección social en España y su convergencia con la Unión europea, (mimeo).

ORGANIZACIÓN INTERNACIONAL DEL TRABAJO, (1999). Extensión de la protección social en sa lud a los grupos excluidos de América La tina y el Caribe, México, OIT/OPS.

PROGRAMA DE LAS NACIONES UNIDADES PARA EL DESARROLLO (PNU) y Consejo Nacional de Coordinación de Políticas Sociales (CNCPS) (2010) República Argentina. Objetivos de Desarrollo del Milenio: rendición de cuentas 2010, PNUD Argentina, Buenos Aires.

REMEDIAR (2006). “El programa Remediar. Gestión y resultados de un modelo innovador en APS". Ministerio de Salud de la Nación, Buenos Aires.

RIVAS, Axel; VERA, Alejandro y BEZEM, Pablo (2010). Radiografía de la educación argentina. CIPPEC / Fundación Arcor / Fundación Roberto Noble, Buenos Aires.

ROCA, Emilia (2010). Asignación Universal por Hijo (AUH): extensión de las asignaciones familiares, en Revista Debate público, Año 1, Nro. 1; Universidad de Buenos Aires, Buenos Aires, Pag. 29-43.

SECO, Martín y ROMO, Marino, (2005). La organización de la seguridad social, Buenos Aires, Fundación Interamericana para el Desarrollo y Formación de Fondos de Pensiones Laborales.

VELEDA, Cecilia (2008). Políticas de inclusión, justicia e integración, CIPPEC, Buenos Aires.

ZADICOFF, P. Y; PAZ, J. (2004). Avus, el genio y Silverix. El programa jefes de hogar: evaluación de objetivos, UCEMA-CONICET, Bs. As.

1 Se refiere, fundamentalmente, a los sesgos que afectarían negativamente las actividades de exportación, el sector agropecuario (urban bias) y el factor trabajo. Una profundización sobre este punto en (DEL VALLE, 2001).

${ }^{2}$ Como ejemplo del aprovechamiento de los beneficios, hasta 1996 se citaban los casos de algunos países del este asiático donde la estrategia basada en las exportaciones industriales como motor del crecimiento generó una gran cantidad de empleo, contribuyó a reubicar la fuerza de trabajo de la agricultura hacia actividades de mayor productividad e incentivó un mejoramiento generalizado de la productividad por lo que se produjo un aumento creciente en los salarios y reducción de la desigualdad salarial (FIELDS, 1994: 395-414).

3 2. A partir de marzo de 2012, en la categoría "Otros Regímenes" se incluye a los trabajadores "No Obligados al SIPA" y a los declarados por Regímenes Provinciales, Municipales y Cajas Profesionales (En función de la Res. MEyFP № 33/2011). Para esta nueva clasificación, en el caso de que un trabajador se encuentre en más de un régimen, la selección del mismo se realiza de acuerdo al orden de prioridad presentado en el cuadro, con independencia de la remuneración o renta de referencia declaradas (MTEySS; 2014).

${ }^{4}$ Las personas que ingresaron por medio del plan de inclusión previsional eran aquellos que presentaban problemas de precarización del mercado laboral por lo que no cumplían con los requisitos de las contribuciones. Estas jubilaciones, (BERTRANOU, 2010: 20-21) las caracteriza como parte de un esquema "semi-contributivo"

${ }^{5}$ Desde 1934, ya existían asignaciones consistentes en un subsidio por maternidad y algunos beneficios por hijo para los trabajadores de sectores específicos, como el bancario. Sin embargo, no es hasta 1957 que se establece un sistema más integral, con la conformación de la Caja de Asignaciones Familiares para el Personal de la Industria (CASFPI). Otros sectores siguieron esta tendencia, constituyendo sus propias Cajas de Asignaciones Familiares. Luego, en 1968, se unificaron normativamente las distintas cajas, aunque se mantuvieron administradas en forma independiente como Cajas de Subsidios y Asignaciones Familiares.

${ }^{6}$ El derecho de los trabajadores y trabajadoras asalariados desocupados a recibir un SEGURO POR DESEMPLEO está establecido por la Ley №24.013 Nacional de Empleo. en su Título IV, la Ley №25.191 de Trabajadores Rurales y la Ley №25.371 del Sistema Integrado de Prestaciones por Desempleo para los Trabajadores comprendidos en el Régimen de la Construcción.

${ }^{7}$ Programa de Respaldo a Estudiantes de Argentina (PROGRESAR).

${ }^{8}$ Según el artículo $1^{\circ}$ de la Ley $N^{\circ} 24.714$, a partir del $1^{\circ}$ de noviembre de 2009, el Régimen de Asignaciones Familiares se basa en un subsistema contributivo fundado en los principios de reparto de aplicación a los trabajadores que presten servicios remunerados en relación de dependencia en la actividad privada, beneficiarios de la Ley sobre Riesgos de Trabajo y beneficiarios del seguro de desempleo; un subsistema no contributivo de aplicación a los beneficiarios del Sistema Integrado 
de Jubilaciones y Pensiones y beneficiarios del régimen de pensiones no contributivas por invalidez; un subsistema no contributivo de Asignación Universal por Hijo para Protección Social, destinado a aquellos niños, niñas y adolescentes residentes en la República Argentina que no tengan otra asignación familiar prevista y pertenezcan a grupos familiares que se encuentren desocupados o se desempeñen en la economía informal.

${ }^{9}$ Según señala Roca, (2010: 36) “...Para verificar y controlar el cumplimiento de estos requisitos se implementó y emitió la Libreta Nacional de Seguridad Social, Salud y Educación para cada uno de los niño/as (más de 3,5 millones de libretas), en la cual constan los datos del titular del beneficio, una declaración jurada sobre su situación laboral y el ingreso percibido Es de señalar que la libreta es un instrumento legal donde deberá acreditarse el cumplimiento de los requisitos, certificados por los responsables tanto del médico en el caso de la vacunación y del control sanitario, como del docente directivo de la escuela a la que concurre el niño/a para el cumplimiento de la escolarización..."

${ }^{10}$ Esto se debió a que los beneficiarios con hijos menores de 18 años pasaron a la AUH y aquellos sin hijos fueron incorporados al SCyE.

${ }^{11}$ En efecto, en un primer momento, los movimientos sociales que tomaron la iniciativa de crearlas eran políticamente afines al gobierno, pero posteriormente aquellos de izquierda reivindicaron, con movilizaciones, poder constituir cooperativas e incorporar a sus miembros y dirigirlas.

12 En sus distintas modalidades y líneas de acción, el Programa de Ingreso Social con Trabajo, actualmente alcanza una cobertura de un promedio variable entre 30 y 36 titulares (personas que cumplen los criterios de elegibilidiady permanencia, impactando en su desarrollo personal, familiar y comunitario) con el siguiente alcance territorial, asociado al distribuidor original (MdDS).

13 "Por un lado, la visión "modernista-tecnocrática" entiende que las personas afectadas por el desempleo, la pobreza y la marginalidad padecen una suerte de enfermedad que hay que tratar con remedios especiales para evitar que no infecte al cuerpo social sano. Estos remedios se expresan en múltiples y diversos programas que pretenden promover las "potenciales" capacidades de esas personas como trabajadores y productores, obligándolas a emplearse en ocupaciones seleccionadas por el Estado; esta sería una especie de sala de espera transitoria hasta que el crecimiento económico y el mercado laboral esté en condiciones de emplearlas de manera normal. Esta visión se combina con otra de carácter "asistencial-represivo" que incorpora a los programas elementos de asistencia solidaria, reeducación y sanción con dos objetivos complementarios: i) evitar el peligro de disrupción social que representa la marginalidad; ii) discriminar entre los "malos" que no aceptan subordinarse a este modo de regulación y los "buenos" que sí lo hacen." (LO VUOLO, 2010; 3)

${ }^{14}$ Su planteo parte del supuesto de que existen mercados laborales competitivos e integrados en una economía. Son varios los motivos por los que no se puede asumir la hipótesis de Levy (2008). Primero, porque resulta difícil sostener el argumento de que el sector informal es el resultado de decisiones óptimas tomadas por empleados y empleadores que se desempeñan voluntariamente en aquel sector. Segundo y, derivada de la primera observación, no existen situaciones de equilibrio por lo que es improbable que los trabajadores del sector informal pudiesen recibir un 'premio salarial' (un salario más elevado que el de los individuos con características similares que trabajan en el sector formal), con el que compensar la ausencia de prestaciones sociales o laborales, que sí reciben los trabajadores del sector formal (como el acceso a la seguridad social). Por último, y en base a los argumentos precedentes, no se puede concluir que los programas sociales con amplia cobertura podrían incrementar la informalidad en una economía, pues gravarían el empleo asalariado formal y el informal sería subsidiado.

${ }^{15}$ Galiani y Weinschelbaum (2007) presentan el modelo económico más completo de informalidad en el mercado de trabajo: la "segmentación" formal/informal surge endógenamente, con empresas grandes y trabajadores calificados en el primer grupo, y empresas pequeñas y trabajadores no calificados en el segundo. Los trabajadores evalúan el paquete de beneficios asociados a la formalidad (con algún espacio para la valoración que tengan de los beneficios prometidos - Summers, 1989) con su costo en términos de menores salarios, mientras que las empresas contraponen el "impuesto" que significan las contribuciones con la probabilidad de ser detectadas y castigadas.

${ }^{16}$ OBS: Referências conforme as normas do país de origem do texto (organizada pelo autor/a). 